\title{
MONITORAMENTO MICROBIOLÓGICO DA MASTITE OVINA NA REGIÃO DE BAURU, SP
}

\section{S.B. Lucheis ${ }^{1}$, G.S. Hernandes ${ }^{1}$, M.Z. Troncarelli ${ }^{2}$}

${ }^{1}$ Apta Centro-Oeste, Unidade de Pesquisa de Bauru, Av. Rodrigues Alves, 40-40, CEP 17030-000, Bauru, SP, Brasil. E-mail: silucheis@apta.sp.gov.br

\section{RESUMO}

As mastites são inflamações agudas ou crônicas da glândula mamária, caracterizadas por alterações físicas, químicas e bacteriológicas no leite. O leite ovino tem ocupado uma importância cada vez maior no mercado, podendo ser utilizado na produção de queijo e outros derivados, contribuindo para o aumento da receita do produtor rural. Entretanto, a mastite pode determinar redução, tanto na quantidade quanto na qualidade do leite produzido, levando à redução do ganho de peso dos cordeiros e causando aumento da mortalidade nos animais. Ressalta-se ainda o aspecto de saúde pública, pela redução do nível de nutrientes, assim como a intensa multiplicação microbiana que pode ocasionar diarreias e outras zoonoses. Pretendeu-se com este trabalho avaliar a frequência de casos de mastite em 159 ovelhas procedentes de vinte pequenas propriedades localizadas em Bauru, SP, e região. Das 309 amostras colhidas, em 97 (31,4\%) foram isolados micro-organismos do gênero Staphylococcus sp., sendo 27,5\% Staphylococcus sp. coagulase negativos e 3,9\% Staphylococcus sp. coagulase positivos. Dos 177 isolamentos, 97 (54,8\%) foram representados pelo gênero Staphylococcus, sendo 57 (58,8\%) obtidos em cultura pura e 40 (41,2\%) em associação. A maioria dos agentes isolados foi sensível aos antimicrobianos utilizados no teste. Assim, pôde-se verificar o isolamento de micro-organismos contagiosos, como Staphylococcus sp. coagulase negativo e positivo, sendo que, assim como na bovinocultura leiteira, medidas de profilaxia para obtenção higiênica do leite são de extrema importância para adquirir-se um produto final de qualidade, e seguro do ponto de vista microbiológico e alimentar.

PALAVRAS-CHAVE: Microbiologia, leite, mastite ovina, Bauru.

\begin{abstract}
MICROBIOLOGICAL MONITORING OF THE REGION OF OVINE MASTITIS BAURU, SP, BRAZIL. Mastitis is an acute or a chronic inflammation of the udder, represented for physical, chemical and bacteriological milk alterations. It is notable that ovine milk represents high economic importance, and it can be used in the production of cheeses and other derivates, contributing for the farmer's recipe enlargement. However, the mastitis in animals can determine the reduction of milk quantity and quality in infected animals. This may determine lambs' weight loss and increase animal's mortality. By the other hand, considering Public Health issues, mastitis can cause milk nutrients losses and promote the microorganisms' multiplication that may lead to diarrheas and to other zoonosis in humans. This study aimed to evaluate 159 sheep mastitis status in 20 small farms located in Bauru (SP) region. Of the 309 colected samples, in 97 (31.4\%) were isolated microorganisms of the genus Staphylococcus sp., which them $27.5 \%$ being coagulase negative Staphylococcus and $3.9 \%$ coagulase positive Staphylococcus. Of 177 isolates, 97 (54.8\%) were represented by the genus Staphylococcus sp., which them 57 (58.8\%) from pure culture and 40 (41.2\%) in association. Most agents isolated were sensitive to antibiotics used in the test. Thus, we could verify the isolation of infectious microorganisms such as coagulase positive and negative Staphylococcus and, as well in dairy cattle, preventive measures to obtain hygienic milk are extremely important in order to get a final product with quality and safe in food and microbiological point of view.
\end{abstract}

KEY WORDS: Microbiology, milk, ovine mastitis, Bauru.

${ }^{2}$ Universidade Estadual Paulista, Faculdade de Medicina Veterinária e Zootecnia, Departamento de Higiene Veterinária e Saúde Pública, Botucatu, SP, Brasil. 


\section{INTRODUÇÃO}

A ovinocultura tem possibilitado a obtenção de uma ampla variedade de produtos de importância fundamental aos seres humanos. Dentre eles, citam-se a carne, a lã, a pele e o leite. O leite ovino é um produto que pode ter valor agregado quando transformado em queijo ou outros derivados, contribuindo para o aumento da receita do produtor rural (UCHOA-CORDERO et al., 2002). Trata-se de um produto economicamente importante na Europa, principalmente em países como Grécia, França, Itália, Espanha e Portugal, os quais buscam implementar pesquisas que possam embasar a elevação da eficiência de produção leiteira. O Brasil é um grande importador deste produto, considerado de alta nobreza pela indústria de queijos. Entretanto, devido à ocorrência de mastites, aproximadamente $46 \%$ das ovelhas são descartadas (WATSON; BUSWELL, 1984).

Alguns fatores relacionados à sanidade são considerados como limitantes na sua exploração. Dentre eles destaca-se a mastite ovina, que vem se tornando um entrave na criação de ovelhas, devido aos prejuízos econômicos que ela acarreta e a limitação na produção de borregos, decorrente do comprometimento funcional da glândula mamária (WATSON; BusWELL, 1984; Costa et al., 2001; MENDONÇA et al., 2005).

Assim como em outras espécies animais, a mastite em pequenos ruminantes desenvolve-se principalmente quando os micro-organismos conseguem romper as barreiras de defesa imunológica do animal, sendo que, normalmente, o ingresso dos agentes microbianos ao interior do úbere ocorre pelo óstio do teto, podendo colonizar apenas a membrana mucosa da cisterna do teto ou até mesmo progredir por toda a glândula mamária (RADOSTiTs et al ., 2007).

Vários patógenos podem causar mastite, mas Staphylococcus spp. são diagnosticados com maior frequência como causa de infecções intramamárias em cabras e ovelhas, efrequentemente sendo responsáveis por casos de mastite subclínica (DRESCHER et al., 2010). Outros patógenos como Streptococcus spp., micro-organismos da família Enterobacteriaceae, Pseudomonas aeruginosa, Mannheimia haemolytica, corinebactérias e fungos podem produzir mastites em pequenos ruminantes, mas em menor proporção (Berriatua et al., 2001; Bergonier: Berthelot, 2003; CONTRERAs et al., 2003; GonZAlo et al., 2004).

Considerando a importância deste tema, pretendeu-se avaliar a frequência de casos de mastite clínica e subclínica em ovinos criados em pequenas propriedades localizadasem Bauru, SP, eregião. Para tanto, realizou-se a análise microbiológica do leite de todos os animais que se apresentavam em lactação; pesquisou-se o perfil de sensibilidade antimicrobiana dos micro-organismos isolados e identificou-se bio- quimicamente as espécies de estafilococos isoladas, tanto em cultura pura quanto em associação com outros micro-organismos.

\section{MATERIAL E MÉTODOS}

As análises microbiológicas foram realizadas no Laboratório de Sanidade Animal da Unidade de Pesquisa de Bauru, pertencente ao Polo Regional de Desenvolvimento Tecnológico dos Agronegócios do CentroOeste, órgão vinculadoà APTA (Agência Paulista de Tecnologia dos Agronegócios) e à Secretaria de Agricultura e Abastecimento (SAA).

\section{Propriedades rurais e animais}

Foram visitadas 20 (vinte) pequenas propriedades, em Bauru, SP, e região, com criação de ovinos da raça Santa Inês, sendo em todas as propriedades ovinos de ambas as finalidades (corte e leite). Cada propriedade possuía uma média de 20 animais. Foi examinado um total de 159 animais em lactação, nove deles apresentando apenas um teto, totalizando 309 amostras coletadas. Não foram realizados exames clínicos nos animais, porém foram observadas as características macroscópicas do leite, tendo-se verificado em algumas amostras desde a formação de grumos pequenos e maiores, presença de flocos e secreção purulenta, além de presença de sangue.

\section{Colheita do leite}

Para a colheita das amostras de leite, os tetos foram lavados previamente com água, e secos com papel toalha descartável. Em seguida, realizou-se a antissepsia do óstio do teto com álcool iodado e, imediatamente, procedeu-se a colheita do leite. As amostras foram acondicionadas em frascos de vidro esterilizados e encaminhadas ao laboratório, sob refrigeração, em caixa isotérmica contendo gelo reciclável.

\section{Cultivo microbiológico}

No laboratório, foram realizados os cultivos microbiológicos com $0,1 \mathrm{~mL}$ de leite em placas de Petri contendo meios de ágar-sangue ovino a 5\% e Mac Conkey, incubando-se a $37^{\circ} \mathrm{C}$. As leituras das placas foram realizadas às 24, 48 e 72 horas, observando-se a morfologia das colônias bacterianas e as características tintoriais dos micro-organismos. Os agentes isolados foram transferidos para meio de caldo-cérebro-coração (BHI) para realização das provas taxonômicas, segundo CARTER; COLE JUNIOR (1990) e Quinn et al. (1994). 


\section{Testes para identificação dos estafilococos isolados}

As amostras de estafilococos isoladas a partir do leite de ovelhas, tanto as de cultura pura quanto as de associação, foram submetidas à prova da coagulase em tubos (QuiNN et al., 1994).

Além do teste de coagulase, as amostras de estafilococos isoladas, tanto as de cultura pura quanto as associadas com outros micro-organismos, foram submetidas a outros testes bioquímicos (maltose, urease, manitol), além de antibiograma com discos de novobiocina (5 ug) e polimixina B (300 unidades), para a identificação das espécies (QUINN et al ., 1994).

\section{Testes de sensibilidade antimicrobiana}

Os testes de sensibilidade antimicrobiana in vitro foram realizados a partir de todos os isolados bacterianos, em placas contendo Agar de Mueller Hinton, utilizando discos de gentamicina $(10 \mu \mathrm{g})$, tetraciclina $(30 \mu \mathrm{g})$, penicilina G (10 U.I.), neomicina $(30 \mu \mathrm{g})$, ampicilina $(10 \mu \mathrm{g})$, oxacilina $(1 \mu \mathrm{g})$, cefalotina (30 $\mu \mathrm{g})$ e sulfazotrim $(25 \mu \mathrm{g})$.

\section{Análise estatística}

A análise dos resultados foi realizada por cálculos estatísticos descritivos para a titulação com uso de tabelas que representassem a relação entre os microorganismos isolados e o número de isolamentos, bem como a porcentagem de sensibilidade frente a diferentes drogas utilizadas (TANAKA, 2000).

\section{RESULTADOS E DISCUSSÃO}

Da mesma forma que ocorre em bovinos, os agentes etiológicos na mastite ovina são múltiplos (LANGONI et al., 1991; LANGONI et al., 1998 apud REIS, S.R., 2003), representados principalmente por bactérias. Entretanto, outros agentes como leveduras, fungos e vírus também podem estar envolvidos. Nas mastites clínicas em ovelhas leiteiras, ressalta-se a infecção por Staphylococcus aureus, Staphylococcus coagulase negativos, Streptococcus spp., Pasteurella spp., incluindo Mannheimia haemolytica; além de enterobactérias e Corynebacterium spp. (BERGONIER; Berthelot, 2003).

A incidência da doença é variável de acordo com o tipo de criação, condições de higiene e fatores predisponentes. Citam-se a elevada produção leiteira aliada ao fornecimento de rações ricas em proteínas, além de traumas mamários (pastos "sujos" e maus tratos que podem levar a lesões na pele do teto), e o manejo de ordenha (VAz, 1996). Além destes fatores, incluem-se surtos de ectima contagioso, elevada taxa de lotação de animais por área, problemas na conformação do úbere e idade (fêmeas mais velhas são mais suscetíveis). Relata-se ainda a participação de vetores mecânicos, como moscas (LANGONietal., 2004).

As precárias condições higiênicas ambientais levam à contaminação fecal do úbere e tetos. Desta forma, os aspectos higiênicos da ordenha no que se refere ao ordenhador e a ordenhadeira, bem como os inerentes à glândula mamária, devem ser respeitados. Caso contrário, as taxas de infecção serão altas, comprometendo seriamente a exploração por ocasionar perda de leite e lesões severas nas glândulas mamárias, obrigando o descarte dos animais e acarretando custos com tratamento que podem, em certos casos, inviabilizar a produção (LANGONI, 2003).

A gravidade da inflamação varia, podendo classificar-se em mastite clínica e subclínica. A mastite clínica nas ovelhas é tipicamente gangrenosa e leva à morte. A mastite subclínica resulta em diminuição na produção de leite e consequente retardo no crescimento e desenvolvimento do cordeiro, prejudicando o seu desempenho, tornando-o ainda mais suscetível às infecções, com consequente aumento da mortalidade, o que pode inviabilizar a produção (MAVROGENIS et al., 1995; DARIO et al., 1996; PERIs et al., 1996; Costa et al., 2001; MENDONÇA et al., 2005; SANTOS et al., 2007).

A mastite clínica pode ser facilmente percebida, pois o leite torna-se aquoso, podendo conter grumos, pus e sangue. Em casos agudos, os meios mamários infectados apresentam-se inflamados, quentes, sensíveis à palpação e hiperêmicos. Já a forma subclínica é a mais comum na maioria dos rebanhos, sendo a causadora dos maiores prejuízos, pois, ao contrário da forma clínica, esta não apresenta alterações visíveis, tanto no leite quanto no úbere, se espalhando silenciosamente pelo rebanho e determinando fator limitante para a produção de leite.

Além da diminuição da produção, é importante salientar também as alterações do leite quanto a sua composição, com alterações significativas nos teores de gordura, proteína e lactose, que afetam suas propriedades tecnológicas, diminuindo o rendimento de seus subprodutos, como queijos (SARATsiset al., 1999).

Há poucas informações sobre a produção de leite e a ocorrência de mastite em ovinos no Brasil, onde a maioria das raças criadas tem aptidão para a produção de carne ou lã. O primeiro relato de mastite ovina no País foi realizado por FERnANDEs; CARdoso (1985), ao descreverem um surto de mastite por $S$. aureus no Rio Grande do Sul. VAZ (1996), em um levantamento realizado em algumas regiões do Rio Grande do Sul e Santa Catarina, detectou mastite crônica e subclínica causada por diversos agentes, incluindo o $S$. aureus. No Nordeste brasileiro, no Estado de Pernambuco, Costa et al. (2001) relataram a ocorrência da doença $(4,19 \%)$, sob a forma de mastite clínica em ovelhas. 
Tabela 1 - Frequência de micro-organismos isolados em cultura pura e em associação a partir de 309 amostras de leite de ovelhas da Raça Santa Inês, procedentes de Bauru, SP, e região.

\begin{tabular}{|c|c|c|}
\hline Micro-organismo & № & $\%$ \\
\hline Staphylococcus sp.* & 45 & 25,4 \\
\hline Corynebacterium sp. & 12 & 6,7 \\
\hline Staphylococcus sp.** & 12 & 6,7 \\
\hline Streptococcus sp. & 11 & 6,2 \\
\hline Staphylococcus sp. ${ }^{*}+$ Corynebacterium sp. & 10 & 5,6 \\
\hline Micrococcus sp. & 9 & 5,0 \\
\hline Bacillus sp. & 7 & 3,9 \\
\hline Bastonete Gram-negativo & 7 & 3,9 \\
\hline Arcanobacterium pyogenes & 5 & 2,8 \\
\hline Staphylococcus sp. $* * * * *$ & 5 & 2,8 \\
\hline Staphylococcus sp. ${ }^{*}+$ Bacillus sp. & 4 & 2,2 \\
\hline Bacteroides nodosus & 3 & 1,7 \\
\hline Streptococcus sp. ${ }^{* * *}$ & 3 & 1,7 \\
\hline Staphylococcus sp. ${ }^{*}+$ Streptococcus sp. ${ }^{* * *}$ & 3 & 1,7 \\
\hline Staphylococcus sp. ${ }^{*}+$ Staphylococcus sp.**** & 3 & 1,7 \\
\hline Staphylococcus sp. ${ }^{*}+$ Streptococcus sp. & 3 & 1,7 \\
\hline Staphylococcus sp.* + Bastonete Gram-negativo & 3 & 1,7 \\
\hline Staphylococcus sp.* + Arcanobacterium pyogenes & 2 & 1,1 \\
\hline Staphylococcus sp.* + Streptococcus sp. ${ }^{* * * *}$ & 2 & 1,1 \\
\hline Staphylococcus sp. ${ }^{*}+$ Bacillus mycoides & 2 & 1,1 \\
\hline Staphylococcus sp. ${ }^{*}+$ Micrococcus sp. & 2 & 1,1 \\
\hline Bacillus sp. $\beta$ hemolítico $+B$. anthracis & 2 & 1,1 \\
\hline Bacteroides nodosus + Bacillus sp. & 2 & 1,1 \\
\hline Candida sp. & 1 & 0,6 \\
\hline Micrococcus sp. $\beta$ hemolítico & 1 & 0,6 \\
\hline Bacillus sp. & 1 & 0,6 \\
\hline Bacillus sp. $\beta$ hemolítico & 1 & 0,6 \\
\hline Staphylococcus sp. + F. necrophorum ${ }^{* * * * * *}$ & 1 & 0,6 \\
\hline Streptococcus sp. + Corynebacterium sp. & 1 & 0,6 \\
\hline Bacillus sp. + Bastonete Gram-negativo & 1 & 0,6 \\
\hline Corynebacterium sp. + Bastonete Gram-negativo & 1 & 0,6 \\
\hline Staphylococcus sp. ${ }^{*}+$ Bacillus sp. $\beta$ hemolítico & 1 & 0,6 \\
\hline Micrococcus sp. + A. pyogenes & 1 & 0,6 \\
\hline Micrococcus sp. $\beta$ hemolítico + F.necrophorum ${ }^{* * * * * *}$ & 1 & 0,6 \\
\hline F. necrophorum + F. necrophorum ${ }^{* * * * * *} \beta$ hemolítico & 1 & 0,6 \\
\hline F. necrophorum + Bacillus sp. & 1 & 0,6 \\
\hline Bacteroides nodosus + A. pyogenes & 1 & 0,6 \\
\hline Staphylococcus sp. ${ }^{*}+$ Corynebacterium sp. + Bacillus sp. & 1 & 0,6 \\
\hline Staphylococcus sp. ${ }^{*}+$ Streptococcus sp. + A. pyogenes & 1 & 0,6 \\
\hline Streptococcus sp. + Bacillus sp. + Bastonete Gram-negativo & 1 & 0,6 \\
\hline Staphylococcus sp. ${ }^{*}$ Staphylococcus sp. ${ }^{* * * *}$ Corynebacterium sp. & 1 & 0,6 \\
\hline Staphylococcus sp. ${ }^{* * * * * *}+$ Staphylococcus sp. ${ }^{* * * *}+$ Corynebacterium sp. & 1 & 0,6 \\
\hline Staphylococcus sp. ${ }^{*}+$ Bacteroides nodosus + Streptococcus sp. + Corynebacterium sp. & 1 & 0,6 \\
\hline Total & 177 & 100 \\
\hline
\end{tabular}

*Staphylococcus sp. coagulase negativo;

**Staphylococcus sp. coagulase positivo;

***Streptococcus sp. a hemolítico;

*** Streptococcus sp. $\boldsymbol{\beta}$ hemolítico.

*****Staphylococcus sp. $\boldsymbol{\beta}$ hemolítico;

****** Fusobacterium necrophorum;

******Staphylococcus sp. a hemolítico.

Além dos sérios prejuízos econômicos causados pela mastite ovina, ressaltam-se as implicações em saúde pública, devido à redução do nível de nu- trientes e ainda o favorecimento da multiplicação microbiana, que pode ocasionar diarreias e outras zoonoses. Entre estes micro-organismos estão $S$. 
aureus, Escherichia coli O157:H7 produtoras de verotoxinas, Listeria monocytogenes, Yersinia enterocolitica, Salmonella spp., Klebsiella spp., Enterococcusfaecalis etc.

A incidência da mastite ovina é pouco estudada no Brasil. FERNANDES; CARDOSO (1985) relataram pela primeira vez a doença nesta espécie, ao descreverem um surto desta doença em ovelhas no Rio Grande do Sul. De 80 ovelhas da raça Hampshire Down examinadas em propriedades no Rio Grande do Sul, $10 \%$ apresentavam mastite clínica, das quais 8,75\% apresentavam fibrose da glândula mamária e agalaxia. S. aureus foi isolado de todos os casos. As mastites clínicas ocorrem em $5 \%$ das ovelhas lactentes anualmente, com média de 0 a 2,5\%.

No presente estudo, de um total de 309 amostras examinadas, apenas $10(3,2 \%)$ apresentaram características de mastite clínica, variando desde a formação de pequenos grumos à coagulação completa do leite, além da presença de flocos e pus. Três amostras (1\%) apresentaram coloração rósea o que indicava a presença de sangue. Foram examinados 159 animais, nove deles apresentando apenas um teto viável. Do total deamostras avaliadas, 177 (57,3\%) apresentaram crescimento bacteriano, sendo 123 amostras $(69,5 \%)$ com isolamento em cultura pura e 54 amostras $(30,5 \%)$ com isolamento em associação, como pode ser observado na Tabela 1. Não houve isolamento bacteriano em 132 amostras (42,7\%).

Das 309 amostras colhidas, em 97 (31,4\%) foram isolados micro-organismos do gênero Staphylococcus sp., sendo 27,5\% Staphylococcus sp. coagulase negativos e 3,9\% Staphylococcus sp. coagulase positivos. Dos 177 isolamentos, $97(54,8 \%)$ foram representados pelo gênero Staphylococcus, sendo 57 (58,8\%) obtidos em cultura pura e 40 (41,2\%) em associação. As espécies de estafilococos identificadas e suas frequências estão apresentadas na Tabela 2.

Tabela 2 - Frequências de espécies de Staphylococcus isoladas a partir de amostras de leite de ovelhas da raça Santa Inês, procedentes de Bauru, SP, e região.

\begin{tabular}{lcc}
\hline \multicolumn{1}{c}{ Espécie } & Frequência & $(\%)$ \\
\hline S. arlettae & 30 & 30,9 \\
S. lentus & 27 & 27,9 \\
S. hyicus & 28 & 28,9 \\
S. aureus & 11 & 11,3 \\
S. aureus anaerobius & 1 & 1,0 \\
\hline Total & 97 & 100 \\
\hline
\end{tabular}

Nas Tabelas 3 e 4 estão apresentadas as frequências de sensibilidade dos agentes isolados frente às drogas testadas. Verifica-se que a maioria dos agentes isolados foi sensível aos antimicrobianos utilizados no teste.

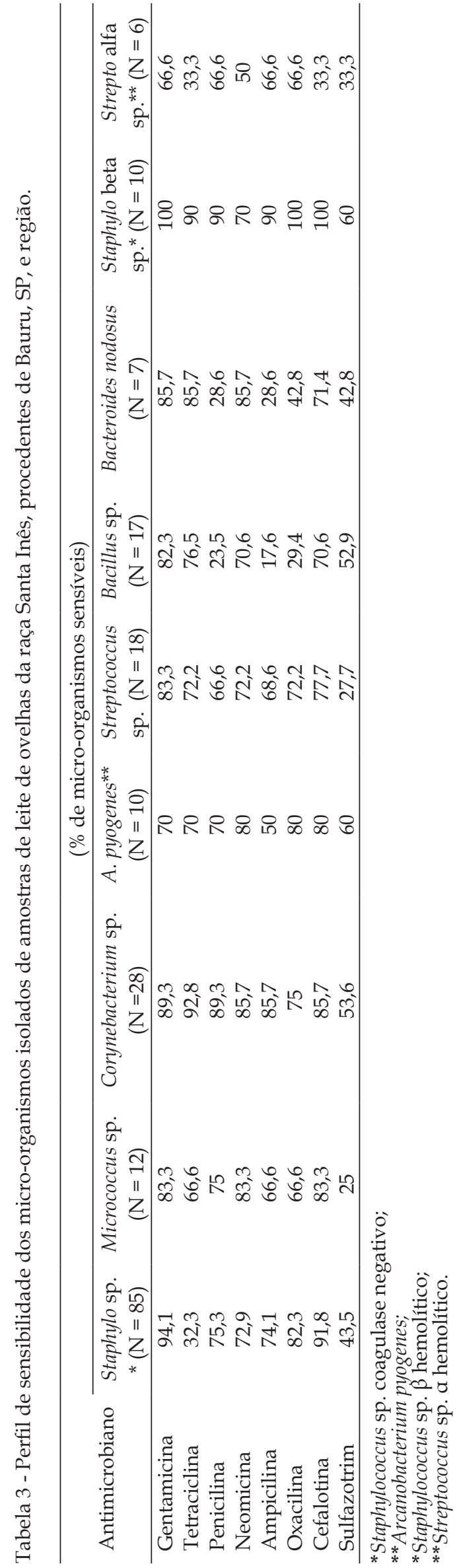




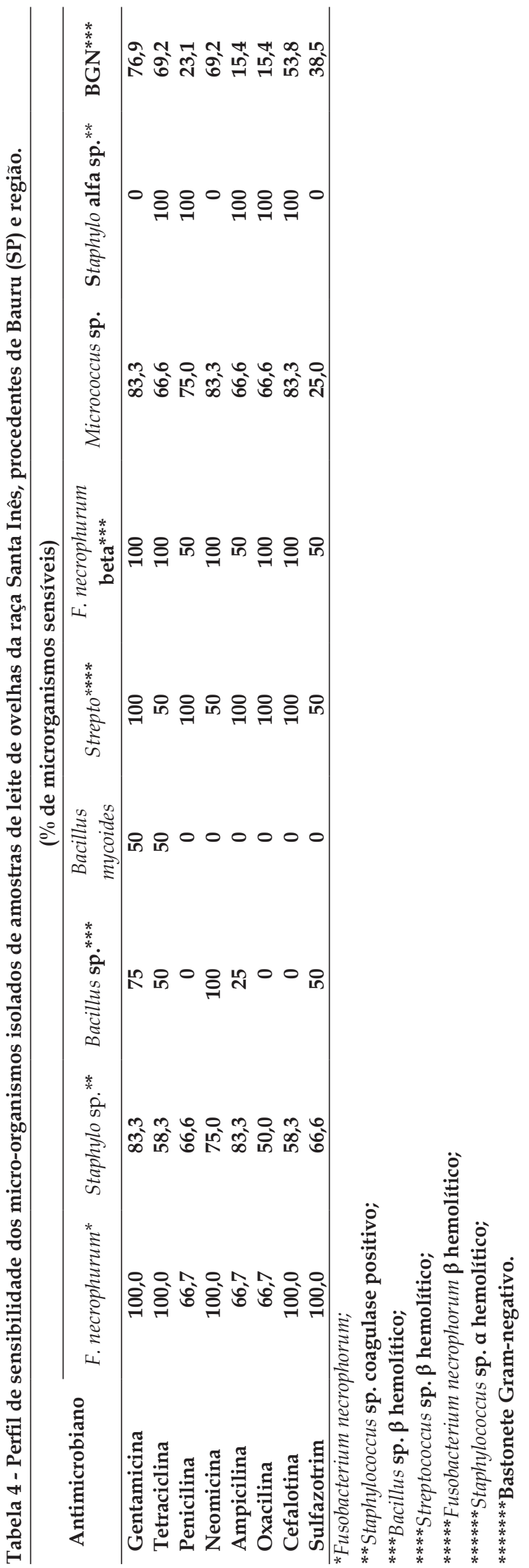

Tradicionalmente, considerava-seque Staphylococcus $\mathrm{sp}$. coagulase negativos não fossem patogênicos ou que apresentassem reduzida patogenicidade para as glândulas mamárias de ruminantes domésticos. Entretanto, outros pesquisadores têm relatado a importância dessas bactérias como agentes etiológicos causadores de mastites subclínicas em ovelhas (Fthenakis; Jones, 1990; Lafi et al., 1998; Pengov, 2001; GonZALO et al., 2002), e também influenciando negativamente no tecido glandular mamário e na composição do leite (BURRIEL, 1997). Com o aumento do interesse na produção de leite e produção de derivados, como o queijo e manteiga, é cada vez maior a necessidade do monitoramento da mastite subclínica (ZADNICK et al., 1993). Estudos têm confirmado que a contagem bacteriana total e a contagem de células somáticas constituem-se em importantes medidas para o controle da mastite subclínica em ovelhas (FtHENAKIs et al., 1991). A elevada contagem de células somáticas no leite, bem como alterações patológicas da glândula mamária, são ocasionadas principalmente por micro-organismos pertencentes ao gênero Staphylococcus spp., sendo o S. aureus e várias cepas de $S$. lentus os principais responsáveis por esses danos.

Apesar de serem isolados em alguns casos de mastite clínica, os estafilococos coagulase negativos são considerados os principais agentes causais de mastite subclínica em ovelhas. No presente estudo, isolaram-se 27,5\% de Staphylococcus sp. coagulase negativos. Este resultado foi semelhante ao obtido por VAZ (1996), que examinou 645 ovelhas e identificou $4,49 \%$ positivas ao exame bacteriológico, com o isolamento de 59,3\% de Staphylococcus sp. coagulase negativos. Outros agentes foram identificados, como S. aureus (7,41\%), Mannheimia (Pasteurella) haemolytica $(3,7 \%)$, Streptococcus spp. (7,41\%), Corynebacterium spp. $(3,7 \%)$ e Micrococcus spp. (3,7\%). Em trabalho realizado por DRESCHER et al. (2010), foram isolados a partir de 163 amostras de leite ovino Stahpylococcus spp. (31,39\%), resultado muito próximo ao obtido no presente estudo, Acinetobacter spp. (10,50\%), Enterobacter aerogenes $(10,50 \%)$, E. coli $(8,20 \%)$ e Aeromonas spp. $(6,70 \%)$.

Corynebacterium spp. e Arcanobacterium pyogenes também são responsáveis por uma proporção significativa de casos de mastite ovina (SARATSIS et al., 1998; LAs HERAs et al., 1999), o que corrobora os resultados obtidos no presente trabalho, com $9,8 \%$ e $4,0 \%$ de isolamentos em cultura pura, respectivamente. Em associação com Staphylococcus sp. coagulase negativo, Corynebacterium sp. foi isolado em $18,5 \%$ das amostras, e Arcanobacterium pyogenes, em 3,7\%.

Ribeiro et al. (1999) avaliaram 321 amostras de leite de ovelhas, com $76 \%$ negativas ao exame microbiológico e $24 \%$ positivas. Foram isolados Staphylococcus spp. $(12,93 \%)$, S. aureus $(3,27 \%)$, Corynebacterium 
spp. (2,65\%), Micrococcus spp. $(2,18 \%)$, Streptococcus spp. (1,4\%), Enterobacteriaceas (0,95\%) e Candida spp. $(0,62 \%)$, semelhante ao que foi verificado no presente estudo, com 9,8\% de isolamentos de Corynebacterium spp. em cultura pura e em 18,5\% associado com Staphylococcus sp. coagulase negativo. Com relação ao Streptococcus sp., o agente foi identificado em cultura pura em $8,9 \%$ dos isolamentos e Micrococcus sp. foi verificado em $7,3 \%$ dos isolamentos.

Com base no exposto, evidencia-se que o isolamento de micro-organismos contagiosos, tais como S. aureus e Corynebacterium spp., sugere que a transmissão ocorra principalmente no momento da ordenha, tanto a partir das mãos do ordenhador, como também de equipamentos e utensílios de ordenha. $S$. aureus é bastante comum na pele e nas mucosas de ovelhas e cabras, e as infecções relacionadas com estas bactérias são normalmente atribuídas à falta de higiene durante a ordenha, além da sucção excessiva pelo cordeiro, ou ainda pelo contato da pele do teto com pastagens contaminadas (ANDERSON et al., 2005).

Além do prejuízo à glândula mamária, ocasionando a mastite, a produção de enterotoxinas pelos micro-organismos também tem especial importância, não sendo apenas restrita à espécie S. aureus. Estudos evidenciaram que espécies coagulase negativas, tais como o Staphylococcus lentus, são capazes de produzir toxinas em condições laboratoriais (PEREIRA et al., 2001), sendo que o agente foi identificado em $27,9 \%$ dos 97 isolamentos de micro-organismos do gênero Staphylococcus spp. As toxinas estafilocócicas são responsáveis por gastroenterites importantes, ocasionando náuseas, vômitos, contrações abdominais, diarreia, sudorese e cefaleia. A intoxicação geralmente não é letal, mas pode evoluir para quadros mais severos, dependendo da suscetibilidade do indivíduo, ao ingerir o leite contendo estas toxinas, constituindo um problema de saúde pública (BALABAN; RASOOLY, 2000).

Sendo assim, devido à elevada complexidade etiológica da mastite ovina e à relevância econômica da exploração leiteira nesta espécie, principalmente para a produção de queijos, esta patologia merece atenção especial. As medidas de profilaxia para obtenção higiênica do leite são de extrema importância para adquirir-se um produto final de qualidade e seguro do ponto de vista microbiológico e alimentar.

\section{CONSIDERAÇÕES FINAIS}

O presente estudo possibilitou a identificação do status de infecção microbiana no leite de ovinos criados na região de Bauru, SP, evidenciando-se o isolamento de micro-organismos contagiosos, como Staphylococcus sp. coagulase negativo e positivo, tanto em cultura pura, quanto em associação com outros agentes. Deve-se salientar que, assim como na bovinocultura leiteira, o manejo de ordenha em ovinos deve ser realizado com extrema higiene, instituindo-se a utilização de antissépticos para o pré e pós-dipping, associado à adequada desinfecção dos utensílios de ordenha. Com isso, é possível o controle dos riscos de infecção, especialmente pelos agentes contagiosos que, além de causarem redução da produção leiteira e menor rendimento industrial, são patógenos de evidente importância em saúde pública.

\section{AGRADECIMENTOS}

Ao Instituto Lauro de Souza Lima de Bauru, SP, pelo suporte com os coelhos e ovinos, a Fernando José Paganini Listoni, pelo auxílio com os bioquímicos e à Fundação de Amparo à Pesquisa do Estado de São Paulo (FAPESP), pela concessão da bolsa de Iniciação Científica Processo 2005/04418-3.

\section{REFERÊNCIAS}

ANDERSON, D.E., HULL, B.L.; PUGH, D.G. Enfermidades da glândula mamária. In: PUGH, D.G. (Ed.). Clínica de ovinos e caprinos. São Paulo: Roca, 2005. 513p.

BALABAN, N.; RASOOLY, A. Staphylococcal enterotoxins: a review. Internal Journal of Food Microbiology, v.61, p.1-10, 2000.

BERGONIER, D.; BERTHELOT, X. New advances in epizootiology and control of ewe mastitis. Livestock Production Science, v.79, p. 1- 16, 2003.

BERRIATUA, E.; ZILUAGA, I.; MIGUEL-VIRTO, C.; URIBARREN, P.; JUSTE, R.; LAEVENS, S.; VANDAMME, P.; GOVAN, J.R. Outbreak of subclinical mastitis in a flock of dairy sheep associated with Burkholderia cepacia complex infection. Journal of Clinical Microbiology, v.39, p.990-994, 2001.

BURRIEL, A.R. Dynamics of intramammary infection in the sheep caused by coagulase-negative staphylococci and its influence on udder tissue and milk composition. Veterinary Record, v.140, n.16, p.419-423, 1997.

CARTER, G.R.; COLE JUNIOR, J.R. Diagnostic procedures in veterinary bacteriology and mycology. 5 . ed. San Diego, Califórnia: Academic Press, 1990. p. 201-209.

CONTRERAS, A.; LUENGO, C.; SANCHEZ, A.; CORRALES, J.C. The role of intramammary pathogens in dairy goats. Livestock Production Science, v.79, p.273-283, 2003.

COSTA, N.A.; MENDONÇA, C.L.; AFONSO, J.A.B.; SOUZA, M.I.; CALADO, A.L.; PIRES, J.R.; COUTINHO, L.T.; SIMÃO, L.C.V.; CAVALCANTE, A.E.L. Ocorrência 
de mastite em ovelhas atendidas na clínica de bovinos. In: CONGRESSO BRASILEIRO DE MEDICINA VETERINÁRIA, 28., 2001, Salvador, BA. Resumos. Salvador, 2001. p.123.

DARIO, C.; LAUDADIO, V.; CORSALINI, T.; BUFANO, G.; BUONAVOGLIA, C. Subclinical mastitis in sheep: occurence/aetiology and milk production in different genetic types. Agricoltura Mediterranea, v.126, p.320-325, 1996.

DRESCHER, G.; MATTIELLO, S.P.; PEIXOTO, R.M.; DE VARGAS, A.C.; MACIEL, M.N.; DA COSTA, M.M. da Caracterização bioquímica e perfil de sensibilidade aos antimicrobianos de agentes bacterianos isolados de mastite subclínica ovina na região oeste de Santa Catarina. Ciência Animal Brasileira, v.11, n.1, p.188-193, 2010.

FERNANDES, J.C.T.; CARDOSO, M.R.I. Mamite ovina causada por Staphylococcus aureus. Primeira observação no Brasil. Arquivos da Faculdade de Veterinária, UFRGS, v.13, p.71-74, 1985.

FTHENAKIS, G.C.; JONES, J.E.T. The effect of inoculation of coagulase-negative staphylococci into the ovine mammary gland. Journal of Comparative Pathology, v.102, p.211-219, 1990.

FTHENAKIS, G.C.; EL MASANAT, E.T.S.; BOOTH, J.M.; JONES, J.E.T. Somatic cell counts of ewes'milk. Brazilian Veterinary Journal, v.147, p.575-581, 1991.

GONZALO, C.; ARIZNABARRETA, A.; CARRIEDO, J.A.; SAN PRIMITIVO, F. Mammary pathogens and their relationship to somatic cell count and milk yield losses in dairy ewes. Journal of Dairy Science, v.85, n.6, p.1460-1467, 2002.

GONZALO, C.; TARDAGUILA, J.A.; DE LA FUENTE, L.F.; SAN PRIMITIVO, F. Effects of selective and complete dry therapy on prevalence of intrammamary infection and on milk yield in the subsequent lactation in dairy ewes. Journal of Dairy Research, v.71, p.33-38, 2004.

LAFI, S.Q.; AL-MAJALI, A.M.; ROUSAN, M.D.; ALAWNEH, J.M. Epidemiological studies of clinical and subclinical ovine mastitis in Awassi sheep in northern Jordan. Preventive Veterinary Medicine, v.33, n.1/4, p.171-181, 1998.

LANGONI, H.; DOMINGUES, P.F.; PINTO, M.P.; LISTONI, F.J.P. Etiologia e sensibilidade bacteriana da mastite bovina subclínica. Arquivo Brasileiro de Medicina Veterinária, v.43, n.6, p.507-515, 1991.

LANGONI, H.; DA SILVA, A.V. da; CABRAL, K. G.; DOMINGUES, P. F. Etiologic aspects on bovine mastitis: Aerobic bacterial flora. In: PANAMERICAN CONGRESS ON MASTITIS CONTROL AND MILK QUALITY, 1., 1998, Mérida, Mexico. Proceedings. Mérida, Mexico, 1998. p.468-480 apud REIS, 2003.
LANGONI, H. Controle de afecções das glândulas mamárias: Aspectos etio-epidemiológicos, de diagnóstico, tratamento e profilaxia nas mastites ovinas. In: ENCONTRO DE CAPRINOVINOCULTORES DE CORTE DA BAHIA, 3., 2003, Salvador. Anais. Salvador, 2003. p.66-80.

LANGONI, H.; ARAUJO, W.N.; VICTORIA, C. Contribuição ao estudo das mastites ovinas: aspectos microbiológicos. Napgama, v.7, n.1, p.3-6, 2004.

LAS HERAS, A.; DOMÍNGUEZ, L.; FERNÁNDEZGARAYZÁBAL, J.F. Prevalence and aetiology of subclinical mastitis in dairy ewes of the Madri region. Small Ruminants Research, v.32, p.21-29, 1999.

MAVROGENIS, A.P.; KOUMAS, A.; KAKOYIANNIS, C.K.; TALIOTIS, C.H. Use of somatic cell counts for the detection of subclinical mastitis in sheep. Small Ruminants Research, v.17, p.78-84, 1995.

MENDONÇA, C.L.; AFONSO, J.A.B., COSTA, N.A. Mastite em ovelhas. Veterinária e Zootecnia CRMV-PE, Recife, v.25, np.7, 2005.

PENGOV, A. The role of coagulase-negative Staphylococcus spp. Aand associated somatic cell counts in the ovine mammary gland. Journal of Dairy Science, v.84, n.3, p.572-574, 2001.

PEREIRA, M.L.; CARMO, L.S.; PEREIRA, J.L. Comportamento de estafilococos coagulase negativos pauciprodutores de enterotoxinas em alimentos experimentalmente inoculados. Ciência e Tecnologia Alimentar, v.21, p.171-175, 2001.

PERIS, C.; DIAZ, J.R.; FERNANDEZ, N.; RADRIGUEZ, M., RUBINO, R. Effect of subclinical mastitis on milk yield of Manchega ewes: preliminary results. In: Proceedings of Somatic Cells and Milk of Small Ruminants., Wageningen Pers, Wageningen: EAAP Publication, , 1996. p.203-206.

QUINN, P.J.; CARTER, M.; MARKEY, B.; CARTER, G. Clinical veterinary microbiology. London: Wolfe Publishing, 1994. 648p.

RADOSTITS, O.M.; GAY, C.C.; BLOOD, D.C.; HINCHCLIFF, K.W. Veterinary medicine. A textbook of the diseases of cattle, horses, sheep, pigs and goats. 10.ed. Philadelphia, PA: Saunders/Elsevier, 2007. 2156p.

REIS, S.R.; SILVA, N.; BRESCIA, M.V. Antibioticoterapia para controle da mastite subclinica de vacas em lactação. Arquivo Brasileiro de Medicina Veterinária e Zootecnia, v.55, n.6, p.651-658, dez., 2003.

RIBEIRO, F.C.; LANGONI, H.; MENDONÇA, L.J.P.; ARAUJO, W.N. Aspectos microbiológicos e perfis de sensibilidade de patógenos na mastite ovina. In: ENCONTRO DE PESQUISADORES EM MASTITES, 3., 1999, Botucatu. Anais. ..Botucatu: FMVZ / UNESP, 1999. p.135. 
SANTOS, R.A.; MENDONÇA, C.L.; AFONSO, J.A.B.; SIMÃO, L.C.V. Aspectos clínicos e característicos do leite em ovelhas com mastite induzida experimentalmente com Staphylococcus aureus. Pesquisa Veterinária Brasileira, v.27, n.1, p.6-12, 2007.

SARATSIS, P.; LEONTIDES, L.; TZORA A.; ALEXOPOULOS, C.; FTHENAKIS, G.C. Incidence risk and aetiology of mammary abnormalities in dry ewes in 10 flocks in southern Greece. Small Ruminants Research, v.37, p.173-183, 1998.

SARATSIS, P.; ALEXOPOULOS, C.; TZORA, A.; FTHENAKIS, G.C. The effect of experimentally induced subclinical mastitis on de milk yield of dairy ewes. Small Ruminants Research, v.32, p. 205-209, 1999.

TANAKA, M. Estatística. São Paulo: Makron books, 2000.

UCHÔA-CORDERO, M.A.; HERNANDEZ, G.T.; ALFAREO, A.E.O.; ROQUE, L.V; MANDEVILLE, P.B. Milk yield and composition of Rambouillet ewes under intensive management. Small Ruminants Research, v.43, p.269-274, 2002.

VAZ, A.K. Mastite em ovinos. A Hora Veterinária, n.93, p.75-78, 1996.

WATSON, D.L.; BUSWELL, J.F. Modern aspects of sheep mastitis. British Veterinary Journal, v.140, p.529-534, 1984.

WINTER, P. ; SCHILCHER, F. ; FUCHS, K. ; COLDITZ, I.G. Dynamics of experimentally induced Staphylococcus epidermidis mastitis in East Friesian milk ewes. Journal of Dairy Research, v.70, np.157-164, 2003.

ZADNICK, T.; PENGOV, A.; MIJOVI, E.; LIPUI, E.; POGA NIK, M. Somatic cell counts and ewes' milk composition. In: SLOVENIAN VETERINARY CONGRESS, 1., 1993, Portoro. Proceedings. Portoro, Slovenia, 1993.

Recebido em 2/6/09

Aceito em 25/7/10 